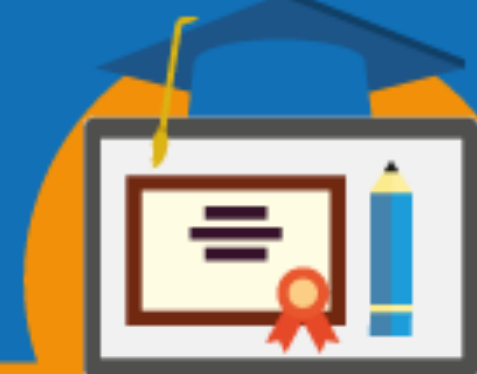

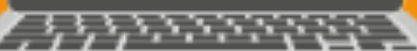

\section{AS TECNOLOGIAS DIGITAIS NAS PRÁTICAS EDUCATIVAS DA EDUCAÇÃO DE JOVENS E ADULTOS NO INSTITUTO FEDERAL DE GOIÁS}

\author{
Lenir de Jesus Barcelos Coelho \\ Instituto Federal de Educação, Ciência e Tecnologia de Goiás \\ lenirbarcelos.mestrado@gmail.com \\ Cláudia Helena dos Santos Araújo \\ Instituto Federal de Educação, Ciência e Tecnologia de Goiás \\ helena.claudia@gmail.com
}

Eixo 6 - Tecnologias e mediações pedagógicas

\section{RESUMO}

Este escrito integra um estudo em andamento, com objetivo de investigar o uso das tecnologias nas práticas educativas da EJA no IFG. Justifica-se em razão das poucas pesquisas sobre o tema, identificados a partir da revisão de literatura realizada em quatro periódicos da CAPES, (2013 a 2018) e pela importância do tema para a educação. Trata-se de uma abordagem qualitativa, do tipo documental e pesquisa de campo, cujos instrumentos de coleta de dados são: questionário, observação em sala de aula, entrevista e leitura do Projeto Pedagógico dos Cursos investigados e do Projeto Político Pedagógico Institucional. Propõe a elaboração um produto educacional na categoria Material Pedagógico Formativo abordando a temática pesquisada com possibilidade de utilização na formação a distância.

Palavras-chave: Educação. Tecnologias. EJA. EPT.

\section{Introdução}

$\mathrm{Na}$ atualidade, as tecnologias digitais têm influenciado as formas que as pessoas se comunicam e aprendem. Portanto, por ser a educação formal um espaço de apropriação da cultura historicamente produzida, bem como de formação do homem na sua integralidade (PARO, 2010), é colocado à escola, enquanto instituição formal de ensino, o desafio de ofertar aos alunos o acesso às tecnologias como possibilidades de aprendizagens dos mais variados conteúdos. 
A partir desse pressuposto, considera-se relevante o uso das tecnologias digitais na Educação Profissional e Tecnológica (EPT), em especial, no âmbito da modalidade Educação de Jovens e Adultos (EJA), tendo em vista que esses sujeitos educativos estão inseridos em um contexto histórico e cultural em que as tecnologias estão presentes, propiciando mudanças nos modos de vida e podendo contribuir para a sua formação. Compreende-se que a EPT, sobretudo na modalidade de EJA, deve ter como base os conceitos de politecnia e de formação omnilateral, a partir da integração do trabalho, da ciência, da cultura e da tecnologia, possibilitando ao indivíduo a formação integral e emancipadora (RAMOS, 2008).

O conceito de politecnia aqui abordado é compreendido num sentido político, que consiste em compreender o trabalho como princípio educativo no intuito de realizar a superação da dicotomia entre trabalho manual e trabalho intelectual por meio da integração das dimensões intelectual e produtiva (RAMOS, 2008).

$\mathrm{Na}$ intenção de perscrutar a revisão de literatura dessa pesquisa, a partir dos princípios teóricos e metodológicos dos estudos científicos já realizados, considerou-se o levantamento bibliográfico sobre tecnologia e EPT realizado por Silva (2019) no portal de periódico da Coordenação de Aperfeiçoamento de Pessoal de Nível Superior (CAPES), no período 20132018. O autor teve como corpus quatro periódicos especializados nas áreas de Educação e Ensino, em razão de ter esses o maior número de trabalhos publicados sobre o tema.

A pesquisa se justifica em razão dos poucos estudos sobre o uso das tecnologias na EJAEPT e por considerar que a EPT se configura como uma necessidade para a classe trabalhadora. Desse modo, tenciona a integração entre educação e trabalho (CIAVATTA 2014), compreendendo os jovens e adultos estudantes da EJA-EPT como sujeitos inseridos num contexto histórico e cultural em que as tecnologias estão presentes. Desse modo, apresenta-se a construção do campo empírico da pesquisa que tem como objetivo analisar os usos das tecnologias digitais nas práticas educativas na Educação Profissional e Tecnológica na modalidade EJA do IFG, Câmpus Anápolis no caminho do seguinte questionamento: Quais os usos das tecnologias digitais nas práticas educativas na Educação Profissional e Tecnológica na modalidade EJA do Instituto Federal de Goiás, Câmpus Anápolis? 


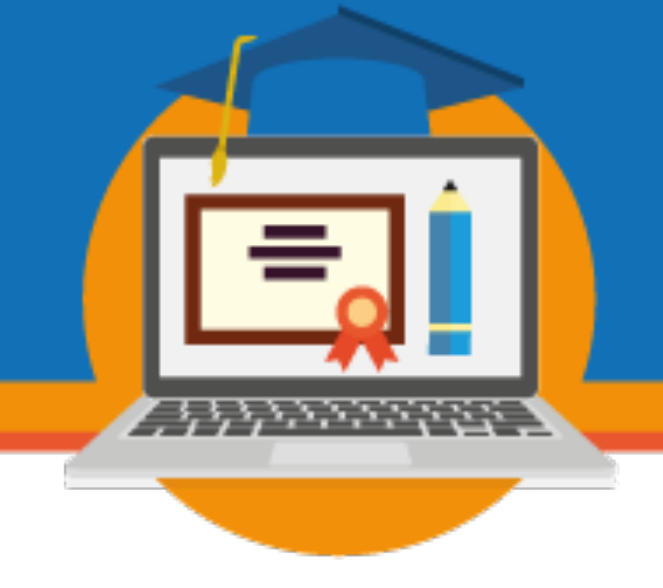

\section{A construção do campo empírico}

Trata-se de uma pesquisa qualitativa, fundamentada nos pressupostos do pensamento dialético, do tipo documental e de campo. Tem como universo de pesquisa os cursos Técnicos Integrado em Secretaria Escolar e Técnico Integrado em Transporte de Cargas, ofertados na modalidade de Educação de Jovens e Adultos pelo IFG Câmpus Anápolis. Os sujeitos participantes se constituem de docentes destes cursos, aos quais será aplicado um questionário por meio de formulário eletrônico. Serão realizadas observações das aulas de dois professores de cada curso, sendo dois da área básica e dois da área profissionalizante, perfazendo o total de quatro professores, com os quais será também realizada uma entrevista semiestruturada.

A pesquisa documental consiste na leitura e análise dos Projetos Pedagógicos dos cursos investigados e no Plano Político Pedagógico Institucional vigente do IFG, no sentido de averiguar como as tecnologias são abordadas nesses documentos. $\mathrm{O}$ estudo fundamenta, do ponto de vista metodológico, em Ludke e André (1986); Sánchez Gamboa (2014) dentre outros, por considerar que estes autores contribuem para a compreensão dos significados existentes no contexto investigado, considerando os procedimentos como práticas sociais.

Por serem as tecnologias digitais na EPT-EJA o objeto de estudo desta pesquisa tendo, dessa forma, proximidade com o estudo de Silva (2019), considerou-se os quatro periódicos utilizados naquele estudo como fontes para revisão da literatura que contribui para justificar a relevância da pesquisa, a saber: Revista Brasileira de Educação Profissional e Tecnológica; Revista Educação e Tecnologia; Revista de Estudos e Pesquisas sobre Ensino Tecnológico e Revista Novas Tecnologias na Educação (RENOTE).

No levantamento bibliográfico realizado, foram encontrados 36 artigos nos periódicos considerados para a revisão bibliográfica. O estudo foi classificado conforme os descritores empregados na pesquisa, sendo encontrados 29 artigos correspondentes ao descritor Educação e Tecnologias Digitais; 03 artigos relacionados com o descritor Educação Profissional e Tecnologias Digitais e 04 referentes ao descritor EJA EPT e Tecnologias Digitais. No que tange

III SEMINÁRIO DE EDUCAÇÃO A DISTÂNCIA

Diálogos sobre EaD e uso das TDIC na educação: regulamentação em tempos recentes 3 a 6 de novembro de 2020 - Brasília/DF - Online 


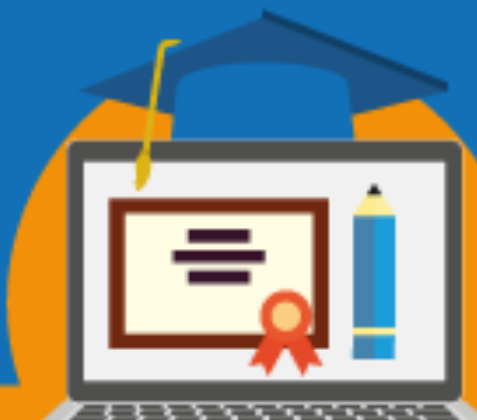

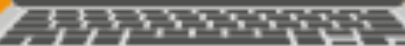

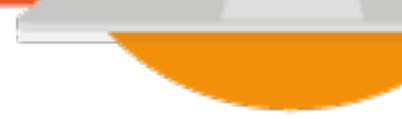

ao descritor "Educação e tecnologias digitais", 09 artigos abordam a formação inicial ou continuada do docente com enfoque no uso das tecnologias digitais e outros 20 abordam o uso destas no processo educativo por meio de atividades que considerem a realidade dos sujeitos envolvidos no processo, bem como os objetivos propostos.

Observou-se nos estudos realizados a concepção de tecnologia como instrumento pedagógico possível de contribuir na qualidade do processo de ensino e aprendizagem a partir da mediação do professor. No entanto, a insegurança dos docentes é apontada como um dos fatores que dificultam o uso da tecnologia no ambiente escolar, o que é atribuído à ausência de estudos sobre o tema nos cursos de formação inicial e nas ações de formação continuada.

Assim, no intuito de proporcionar formação em educação profissional e tecnológica, visando a produção de conhecimentos nas práticas educativas em contextos reais de ensino, formais, não formais ou informais, objetiva-se a construção de um produto educacional. Desse modo, no desenvolvimento deste estudo, propõe-se a elaboração de um Material Didático Formativo - MDF que poderá ser utilizado na Educação a Distância (EaD) de sujeitos educativos que estudam a educação e mediações pedagógicas, que emergirá dos dados da pesquisa e será fundamentado nos estudos sobre a temática, tendo o propósito de contribuir para a formação continuada dos profissionais da educação que atuam, principalmente, na EJA.

No Material Didático Formativo proposto será apresentada a história da EPT no Brasil, as relações tecnologia, educação e EPT, possiblidades de formação a distância desta temática, bem como as questões da tecnologia na EJA. Além de apresentar essas temáticas, visa propor ações didáticas que utilizam a tecnologia e contribuem na formação dos sujeitos educativos nesta modalidade de ensino. Para tanto, a pesquisa se referencia em alguns estudiosos que respaldam teoricamente as reflexões sobre a EPT-EJA, as tecnologias digitais e as práticas educativas, no sentido de contribuírem com o aprofundamento das questões levantadas.

\section{Referencial teórico}


Visando compreender os usos das tecnologias digitais na educação como construtos históricos e sociais, cujas propostas estão relacionadas aos objetivos a elas atribuídos, recorrerse-á às autoras Moraes e Peixoto (2017) e Peixoto (2016).

No que se refere ao conceito de tecnologia, o estudo tem como aporte Álvaro Vieira Pinto (2005), que avança nas considerações sobre o sentido ideológico implícito nos discursos dos detentores dos meios de produção. No sentido etimológico, compreende-se como o estudo da técnica enquanto fruto da ação do homem em sua relação com o mundo.

A técnica como um ato humano, portanto, não pode ser concebida como um dado imediato, mas como mediações produzidas pelas ações do homem sobre a natureza. Nesse sentido, o conceito de tecnologia está articulado ao ato produtivo, ou seja, ao trabalho, visto que o conjunto de tecnologias construídas é desenvolvido de acordo com o modo como o homem produz a vida.

Na intenção de aprofundar as reflexões sobre tecnologia e educação, a pesquisa recorre aos estudos de Andrew Feenberg (2003), estudioso da filosofia da tecnologia que discute sobre a tecnologia e a sociedade. Busca-se problematizar as perspectivas ideológicas e a perspectiva crítica da tecnologia, com base nas concepções de tecnologia presentes no instrumentalismo, no substancialismo, no determinismo e nas teorias críticas da tecnologia.

As teorias instrumentalistas compreendem as tecnologias como instrumentos neutros, subjugados à vontade humana com fim nelas mesmas, que não estão relacionadas aos valores que caracterizam os contextos socioculturais. Por outro lado, as teorias de cunho substancialistas conceituam a tecnologia a partir da interpretação da forma de poder exercido sobre o homem, agregadas de valores substanciais que determinam sua relação com o contexto no qual está inserida. Na perspectiva das teorias deterministas, a tecnologia não pode ser controlada pelo homem, pelo contrário, é ela quem o controla, haja vista que delineia a sociedade, conforme as exigências da eficiência e do progresso (FEENBERG, 2003).

Do ponto de vista da teoria crítica, as tecnologias não são consideradas neutras, e não podem ser caracterizadas sem considerar o contexto social onde estão inseridas, podendo exercerem influências sobre o homem e a organização social e/ou serem influenciadas por ele, 
visto que estão sujeitas às mudanças resultantes da ação do homem sobre elas.

A percepção de tecnologia em que esta pesquisa se fundamenta está respaldada na percepção crítica de Feenberg (2003), visto que investiga os usos das tecnologias nas práticas pedagógicas na modalidade EJA-EPT, considerando as características sócio-histórica e cultural dos sujeitos envolvidos, bem como dos espaços em que as ações pedagógicas com o uso dessas tecnologias são desenvolvidas.

Para o aprofundamento da compreensão da Educação Profissional e Tecnológica como espaço de formação para a superação das desigualdades existentes entre as classes sociais, por meio da integração entre educação e trabalho como uma possibilidade de formação politécnica, integral e omnilateral, a pesquisa embasa em Ciavatta (2014); Frigotto (2007); Ramos (2008), dentre outros.

O conceito de politecnia se ampara nos pressupostos do materialismo histórico dialético, e tem o trabalho como princípio educativo no sentido ontológico da formação humana, divergindo da lógica capitalista de educação, cuja proposta é a formação fragmentada e alienada para a classe trabalhadora. Nesta perspectiva, compreende-se que a formação integral somente é possível pela superação da dualidade fundada entre o trabalho manual e trabalho intelectual, pelo domínio dos fundamentos científicos das diferentes técnicas que caracterizam o processo de trabalho produtivo moderno da unidade entre formação profissional e formação intelectual.

Deste modo, no intuito de proporcionar o estudo da EJA-EPT em sua interlocução com as tecnologias digitais a partir de possibilidades em formação a ser realidade a distância é que conceitua-se EaD como “[...] uma prática social educativa-dialógica de um trabalho coletivo, de autoria e colaborativo [...] integrada ao uso significativo das tecnologias de informação e comunicação, voltada para a formação crítica, autônoma e emancipadora” (LIMA, 2014, p. 60).

Assim, dialoga-se com Alonso (2005) quando enfatiza que a $\mathrm{EaD}$ deve estar fundamentada nos processos interativos, que permitam o encontro entre os atores do processo educacional para a construção dos saberes necessários à formação.

Considera-se que a proposta de integração dos currículos da educação profissional e educação básica na EPT-EJA, tem relevância por ser pautada no princípio de educação 
igualitária que propicie o acesso do sujeito aos conhecimentos e à cultura, construídos historicamente pela humanidade. Dessa forma, pode possibilitar ao educando a realização de escolhas que o faz sujeito de transformações, na medida em que oferta condições de construir caminhos para a produção da vida, sendo um deles, o próprio trabalho como princípio educativo. Ou seja, de modo que o trabalho, nesta perspectiva, seja capaz de propiciar a ação do sujeito para a transformação da sociedade, como elucida Castro, Machado e Vittorete (2010); Paro, (2010) e Ramos (2008).

\section{Considerações em trânsito}

Na revisão de literatura foi possível observar o entendimento da importância das propostas de uso dos recursos tecnológicos no contexto educacional, que considerem os sujeitos envolvidos, os objetivos a serem alcançados, além das formas de uso das tecnologias. Está presente o entendimento do papel do docente como mediador nas propostas pedagógicas de uso das tecnologias (MELO 2018).

Concernente ao descritor Educação Profissional e Tecnológica e Tecnologias digitais, os estudos identificados abordam as práticas em sala de aula nos cursos EPT desenvolvidas com o uso das tecnologias digitais. É evidenciada a importância da formação crítica do docente para o uso das tecnologias, para além do saber-fazer, no sentido de superar a visão instrumental no alusivo às tecnologias no âmbito da educação (PINHEIRO, 2016).

Ainda, relativo ao descritor EJA EPT e Tecnologias Digitais os estudos apontaram para a relevância das tecnologias nas atividades pedagógicas nessa modalidade de ensino.

Percebe-se nos estudos a compreensão da escola como instituição responsável em formar o cidadão e, para tanto, relevante para contribuir para o acesso dos sujeitos às tecnologias, uma vez que o uso dessas no âmbito escolar pode propiciar o desenvolvimento de saberes necessários em outros contextos sociais (SILVA; SANTOS, 2015). Portanto, o levantamento bibliográfico realizado indica e permite concluir para a necessidade do 


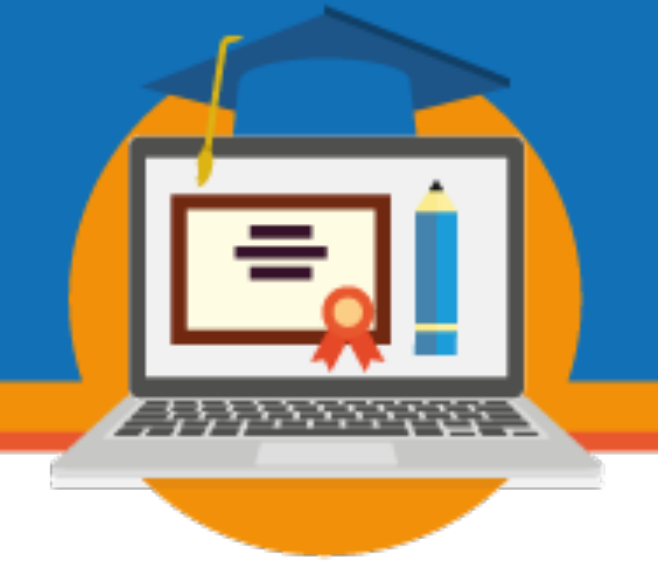

desenvolvimento de pesquisas sobre o tema práticas educativas na EJA-EPT e tecnologias digitais, tendo em vista serem poucos os estudos realizados a respeito.

\section{Referências}

ALONSO, Kátia M. Algumas considerações sobre a educação a distância, aprendizagens e a gestão de sistemas não-presenciais de ensino. In: PRETI, Oreste (Org.) Educação a Distância: Ressignificando Práticas. Brasília: Líber Livro, 2005.

CIAVATTA, M. O ensino integrado, a politecnia e a educação omnilateral: Por que lutamos? Trabalho \& Educação, Belo Horizonte, v.23, n.1, p.187-205, jan.-abr.2014

CASTRO, M. D. R. C; MACHADO, M. M; VITORETTE, J. M. B. Educação Integrada e PROEJA: diálogos possíveis. Revista Educação e Realidade, v 35, n. 1, 2010. p. 151-166.

LIMA, D. C.B.P. Documento técnico contendo estudo analítico das diretrizes, regulamentações, padrões de qualidade/regulação da EAD, com vistas a identificar políticas e indicadores de expansão da Educação Superior em EAD. Brasília: Cne, 2014

FEENBERG, A. O que é fillosofia da tecnologia? 2003. Disponível em https://www.sfu.ca/ andrewf/Feenberg_OQueEFilosofiaDaTecnologia.pdf

FRIGOTTO, G. A relação da educação profissional e Tecnológica com a universalização da Educação básica. 2007. Disponível em: https://www.researchgate.net/publication/228625039_A_relacao_da_educacao_profissional_e _tecnologica_com_a_universalizacao_da_educacao_basica

LÜDKE, Menga; ANDRÉ, Marli E.D.A. Pesquisa em educação: abordagens qualitativas. São Paulo: EPU, 1986. 


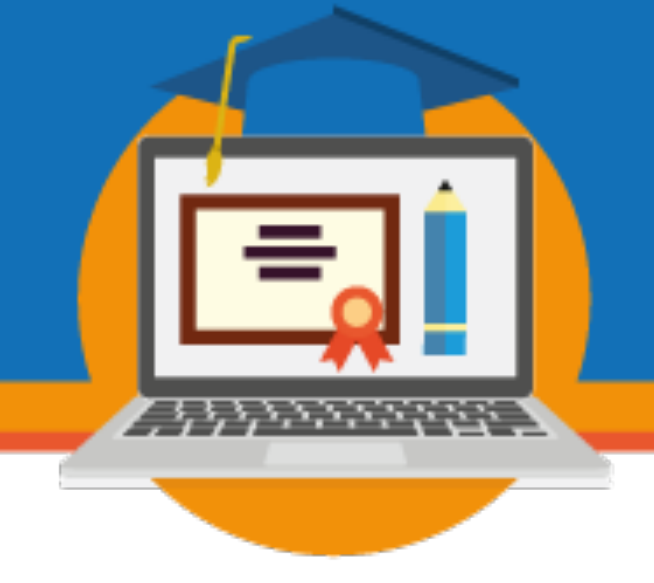

MÉLO, V. N. O. Tecnologias como recursos de ensino e os desafios de implantação na educação. Universidade Tecnológica Federal do Paraná - UTFPR Curitiba - Paraná - Brasil ISSN impresso 1516-280X e ISSN eletrônico 2179-6122 - n.18, p. 37-48, 2018.

MORAES, M. G; PEIXOTO, J. Estado do conhecimento como perspectiva crítica para as pesquisas em educação: "Educação e Tecnologias" em questão. Revista Reflexão e Ação, Santa Cruz do Sul, v. 25, n. 3, p. 321-338, Set./Dez. 2017. Disponível em http://online.unisc.br/seer/index.php/reflex/index. Acesso em 25 de setembro de 2019.

MOURA, D. H. Ensino médio integrado: subsunção aos interesses do capital ou travessia para a formação humana integral? Revista Educação \& Pesquisa, São Paulo, v. 39, n. 3, p. 705-720, jul./set. 2013a.

PARO, V. H. Educação como exercício de poder: crítica ao senso comum em educação. 2. Ed. São Paulo: Cortez, 2010.

PEIXOTO, Joana. Tecnologias e relações pedagógicas: a questão da mediação. R. Educ. Públ. Cuiabá. v. 25. n. 59, p. 367 - 379, maio/ago. 2016.

PINHEIRO, L. A. B. Tecnologia articulada à formação de professores para a educação profissional. Revista de Estudos e Pesquisas sobre Ensino Tecnológico. v. 02, nº 04, ano 2016. Disponível em: https://sistemascmc.ifam.edu.br/educitec/index.php/educitec/article/view/104. Acesso em 21 de setembro de 2019.

SÁNCHEZ GAMBOA, S. Pesquisa em educação: métodos e epistemologias. $2^{\mathrm{a}}$ ed. Chapecó: Argos, 2014.

SILVA, M. N. S. As tecnologias de informação e comunicação no ambiente escolar. Universidade Tecnológica Federal do Paraná - UTFPR Curitiba - Paraná - Brasil - ISSN impresso 1516-280X e ISSN eletrônico 2179-6122 - n.15, p. 56-69, 2015.

VIEIRA PINTO, A. O conceito de Tecnologia. Rio de Janeiro: Contraponto, 2005. $1 \mathrm{v}$. 